\title{
Effect of transmural pressure on preloads and collapse of immature bronchi
}

\author{
P.K. McFawn, H.W. Mitchell
}

Effect of transmural pressure on preloads and collapse of immature bronchi. P.K. McFawn, H.W. Mitchell. (CERS Journals Ltd 1997.

ABSTRACT: Immature airways are highly compliant compared to the adult, suggesting that trachea and bronchi from immature animals may be easily compressed. Although tracheal compression has been extensively studied, the effect of transmural pressure on occlusion of immature bronchi has been neglected.

The transmural pressure at which the lumen closed was determined from the transmittance of pressure along the lumen of isolated bronchi from late-term foetal, 1 and 4 week old pigs. Bronchi from eight cases of sudden infant death syndrome (SIDS) were also studied. In several experiments, smooth muscle tone was produced either by electrical field stimulation or carbachol challenge, and the relationship between active muscle tone and resting transmural pressure was studied.

Bronchi from foetal, 1 and 4 week old pigs were occluded by intraluminal pressures of $-4,-5$ and $-24 \mathrm{cmH}_{2} \mathrm{O}$. SIDS bronchi closed at $-11 \mathrm{cmH}_{2} \mathrm{O}$. Histological and endoscopic investigations showed that closure of the bronchi occurred along a plane and was not uniform along the bronchus. Carbachol precontraction increased the transmural pressure required to close bronchi by approximately $5 \mathrm{cmH}_{2} \mathrm{O}$. The relationship between muscle tone and resting pressure was the same in all age groups, except when transmural pressure was at or below closing pressure.

Bronchi from immature animals and human infants are vulnerable to collapse by small changes in transmural pressure. Bronchial closure is partly dependent on smooth muscle tone, particularly in younger animals.

Eur Respir J 1997; 10: 322-329.
Dept of Physiology, The University of Western Australia, Nedlands 6907, Australia.

Correspondence: P.K. McFawn

Dept of Physiology

The University of Western Australia

Nedlands 6907

Australia

Keywords: Airway collapse airway compliance

airway mechanics

bronchus

lung maturation

Received: December 121995

Accepted after revision August 211996

This research was supported by the Sudden Infant Death Syndrome Foundation of Western Australia and the Australian National SIDS Council.
The effect of lung forces on the calibre of intrapulmonary airways is strongly influenced by the stability of the airway, which in turn is associated with the structural components of the bronchial wall and with their compliance. Trachea and bronchi from foetal and newborn animals are more compliant than those from older animals [1-3], suggesting that they would be more easily occluded by changes in transmural pressure. For example, flow through isolated segments of foetal lamb (114-121 days gestation) trachea is stopped by an external pressure of approximately $10-15 \mathrm{cmH}_{2} \mathrm{O}$ [4]. Separate studies suggest that much higher forces are needed to occlude the adult trachea [5-8].

The susceptibility of immature airways in the bronchial tree to transmural forces has not been investigated. Bronchi are structurally different to the trachea and have a continuous layer of smooth muscle, which does not directly insert into the cartilage plates which cover it. This arrangement of cartilage and muscle is likely to give the bronchi mechanical properties different to the trachea. Morphological studies of the trachea and bronchi of adult cats suggest that bronchi are more collapsible than trachea, with considerable distortion of the bronchial wall produced by an intraluminal pressure of $-15 \mathrm{cmH}_{2} \mathrm{O}$ [6].

Airway smooth muscle tone can increase the stability of the airway wall. In the neonate and adult, smooth muscle tone reduces airway compliance [9-12]. Smooth muscle tone may then provide an important mechanism for stabilizing bronchi against compression, particularly in highly compliant immature airways. However, the tone developed by smooth muscle is itself influenced by its operating length. Airway compliance can effect the preload and the operating length of smooth muscle [13]. If bronchial compliance decreases with age, it is possible that the preload on bronchial smooth muscle and the capacity to generate force over a wide range of transmural pressures also changes with development. Neither the length-force relationship of intact bronchi nor the effect of smooth muscle tone on the stability of immature bronchi has been established.

In the present study, the stability of the cartilaginous bronchus before and after birth was investigated. The transmural pressure required to close the bronchial lumen in late term foetal, neonatal (1 week) and weaned (4 week) pigs was determined. The ability of airway smooth muscle to generate tone at a range of transmural pressures and the effect of airway tone on bronchial collapsibility was also studied.

\section{Methods}

Preparation of bronchial segment

Lungs were obtained from freshly killed 1 and 4 week old pigs (Large White/Landrace cross). Lungs of late 
term foetal pig ( $>100$ days of the 115 day gestation) were supplied by a local abattoir. Segments of stem bronchus, approximately $25 \mathrm{~mm}$ long and $2 \mathrm{~mm}$ in internal diameter, were dissected from the lower lobes, as described previously [14]. Lumen volume was determined from the volume of Krebs solution required to fill the bronchus (coefficient of variation $8.6 \%$ ) as described previously [15].

A small number of human lungs $(n=8)$ from autopsies of infants who died of sudden infant death syndrome (SIDS) were obtained from the Western Australian State Coroner. Infant airways were lobar-segmental bronchi but exact generation was difficult to assess and the length and internal diameter varied depending on the tissue available. All bronchi dissected from human lungs were cartilaginous at the distal end.

Bronchial segments were cannulated and mounted in a modified organ bath (fig. 1). The bronchial lumen was connected to a pressure transducer (Motorola MPX2010DP, Phoenix, AZ, USA) to measure intraluminal pressure, and to a micro-syringe to change luminal volume and pressure. When external (adventitial) pressure was altered, a pressure-tight lid was placed on the organ bath, forming a sealed chamber. This chamber was connected to a column of Krebs solution and chamber pressure was controlled by manometry. During experiments involving electrical field stimulation (EFS), platinum ring electrodes were placed around the bronchi and used to deliver square wave direct current (DC) pulses $(70 \mathrm{~V}$, $30 \mathrm{~Hz} 1 \mathrm{~ms}$ pulse width) from a Grass S44 stimulator (Quincy, USA).

\section{Airway collapse}

Two different groups of bronchi were used to determine airway closure, by using either negative intraluminal pressures or adventitially applied pressures. The negative intraluminal pressure required to close bronchial

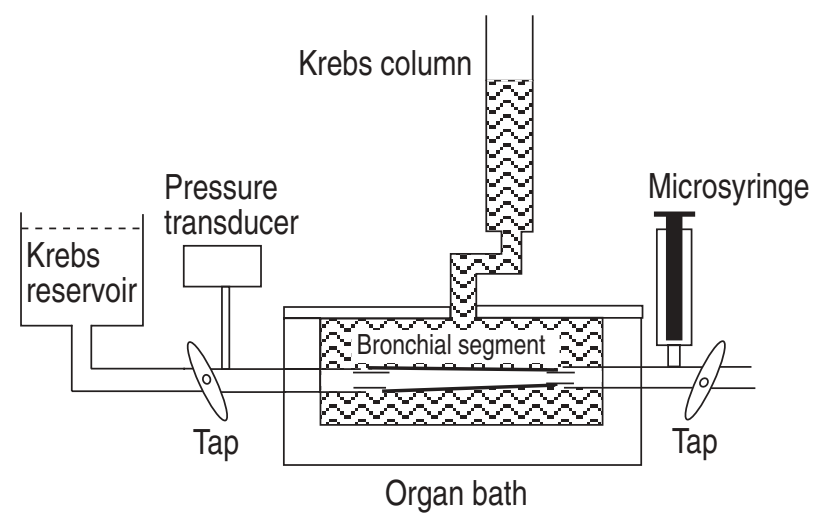

Fig. 1. - Diagram of the experimental apparatus used to measure closing pressures. Bronchial segments were placed in an organ bath containing Krebs solution aerated with $5 \% \mathrm{CO}_{2}$ in $\mathrm{O}_{2}$. The bronchial lumen was connected to a microsyringe at the distal end of the segment and to a pressure transducer at the proximal end. Taps in the apparatus could be opened to flush the lumen with Krebs solution from a reservoir or open the lumen to atmospheric pressure. Intraluminal pressure and volume could be reduced by withdrawing fluid from the lumen using the microsyringe. During experiments that required compression of the bronchi, a lid was placed on the organ bath forming a sealed chamber connected to a column of Krebs solution. The bronchus could then be compressed by increasing the height of Krebs solution in the column. segments was assessed by reducing intraluminal volume (and pressure) at the distal end in small increments (0.02 $\mathrm{mL}$ ), while recording pressure at the proximal end (fig. 1). When the bronchial segment between the syringe (distal end) and pressure transducer (proximal end) closed, the pressure measured no longer changed with further reductions in volume. The pressure at which this occurred was taken as the internal closing pressure.

The compressive force required to close bronchi was determined manometrically by increasing the height of the Krebs column (fig. 1), while the distal end of the bronchus was open to atmospheric pressure. Until compression occluded the bronchial segment, intraluminal pressure remained at 1 atmosphere. Once the lumen closed, however, the intraluminal pressure (recorded at the proximal end) increased with adventitial pressure. The pressure at which this occurred was defined as the external closing pressure. Bronchi were then allowed to recover at $0 \mathrm{cmH}_{2} \mathrm{O}$ transmural pressure before being contracted with $1 \mathrm{\mu M}$ carbachol, and the external closing pressure was then redetermined with the tissue contracted. Contraction with $1 \mu \mathrm{M}$ carbachol produced a 20-30 $\mathrm{cmH}_{2} \mathrm{O}$ increase in intraluminal pressure when the bronchi were contracted under isovolumic conditions (table 1). The length, generation, size and number of bronchi used for each protocol is presented in table 1. At most, two bronchi were taken from each animal.

\section{Active-passive pressure}

The effect of transmural pressure on airway smooth muscle contraction was investigated by EFS of bronchial segments at different resting intraluminal pressures [13]. Passive intraluminal pressure was set by inflating or deflating the segment to the required transmural pressure (with both the microsyringe and pressure transducer connected to the proximal end of the bronchus). After equilibrating for $5 \mathrm{~min}$, the segment was stimulated and active pressure measured. One set of experiments was performed at passive intraluminal pressures

Table 1. - Location and size of bronchial segments used to measure closing pressure

\begin{tabular}{|c|c|c|c|c|}
\hline $\begin{array}{l}\text { Age } \\
\text { weeks }\end{array}$ & $\begin{array}{c}\text { Length } \\
\mathrm{mm}\end{array}$ & $\begin{array}{c}\text { Internal } \\
\text { diameter } \\
\text { mm }\end{array}$ & Generation & $\begin{array}{c}\text { Carbachol } \\
\text { contraction } \\
\mathrm{cmH}_{2} \mathrm{O}\end{array}$ \\
\hline
\end{tabular}

Bronchial segments used to measure internal closing pressure

$\begin{array}{llll}\text { Foetal }(\mathrm{n}=7) & \sim 25 & 1.8 \pm 0.1 & \sim 1-10 \\ \text { One } \quad(\mathrm{n}=8) & \sim 25 & 2.0 \pm 0.1 & \sim 2-13 \\ \text { Four }(\mathrm{n}=8) & \sim 25 & 2.0 \pm 0.1 & \sim 8-16\end{array}$

Bronchial segments used to measure external closing pressure

$\begin{array}{llllll}\text { One } & (\mathrm{n}=7) & \sim 25 & 2.1 \pm 0.1 & \sim 2-12 & 21.7 \pm 5.1 \\ \text { Four } & (\mathrm{n}=10) & \sim 25 & 2.0 \pm 0.1 & \sim 9-17 & 27.4 \pm 3.2\end{array}$

Bronchial segments of similar distal internal diameter were used to examine the effect of age on airway collapse. Internal diameter was kept constant with age by selecting segments from different locations (generations) along the stem bronchus. Bronchus generation is from the proximal to the distal end of the segment, counting the trachea as generation zero. Carbachol contraction is the active pressure generated by a $1 \mu \mathrm{M}$ dose of carbachol. 
of $-5,0,5,10,20$ and $30 \mathrm{cmH}_{2} \mathrm{O}$ (foetal $(\mathrm{n}=12), 1$ week $(n=8)$, and 4 week $(n=8)$ bronchi). A second set of experiments was performed at $5,0,-2.5,-5,-10$ and -20 $\mathrm{cmH}_{2} \mathrm{O}$ ( 1 week $(\mathrm{n}=5)$ and 4 week $(\mathrm{n}=6)$ bronchi). Preliminary experiments showed no decay in active response when the tissues were stimulated every $5 \mathrm{~min}$.

\section{Videoendoscopy}

A fibreoptic endoscope (Olympus SES 1711D, Tokyo, Japan) and CCD camera (JVC TK-1070E, Tokyo, Japan) were used to view the lumen of 1 week old pig bronchi $(\mathrm{n}=8$ bronchi) as described previously [16]. Negative intraluminal pressures were produced by sealing around the endoscope (proximal end) with plasticine and reducing the pressure at the opposite (distal) end of the segment. Closure of the bronchi was observed and recorded on videotape. The effect of airway smooth muscle tone on airway patency was investigated by EFS of collapsed bronchi. In three bronchi that gave good responses to EFS, atropine $(10 \mu \mathrm{M})$ was used to demonstrate that neurotransmission was cholinergic.

\section{Histology}

Bronchi were fixed at intraluminal pressures of 5, -5 or $-20 \mathrm{cmH}_{2} \mathrm{O}$ in phosphate-buffered formalin saline (10\% formalin). Frozen sections $(10 \mu \mathrm{m})$ were cut and stained with haematoxylin (Ajax, Auburn, Australia) and chromotrope 2R (Gurr; BDH, Poole, UK).

\section{Solutions}

The Krebs solution used had the following composition (in $\mathrm{mM}$ ): $121 \mathrm{NaCl}, 5.4 \mathrm{KCl}, 1.2 \mathrm{MgSO}_{4}, 1.2$ $\mathrm{NaH}_{2} \mathrm{PO}_{4}, 25 \mathrm{NaHCO}_{3}, 11.5$ glucose, $2.5 \mathrm{CaCl}_{2}$. The phosphate-buffered saline had the following composition (in mM): $150 \mathrm{NaCl}, 5 \mathrm{NaH}_{2} \mathrm{PO}_{4}, 15 \mathrm{Na}_{2} \mathrm{HPO}_{4}$ and was buffered to $\mathrm{pH}$ 7.2. The drugs used were acetylcholine chloride, carbachol (carbamylcholine chloride) and atropine sulphate, all from Sigma (St. Louis, USA).

\section{Statistics}

Significance among multiple groups was tested by analysis of variance (ANOVA) with Student-NewmannKeuls post hoc test. When only two groups were compared, Student's t-test was used to determine significance. Paired t-tests were used to compare the external closing pressure of relaxed and contracted bronchi. All results are reported as mean \pm standard error of the mean. A p-value of less than 0.05 was considered to be significant.

\section{Results}

\section{Airway collapse}

The distal internal diameter and generation of the bronchi used is shown in table 1 . Internal closing pressures for the bronchi of late term foetal $(-4.47 \pm 0.96$

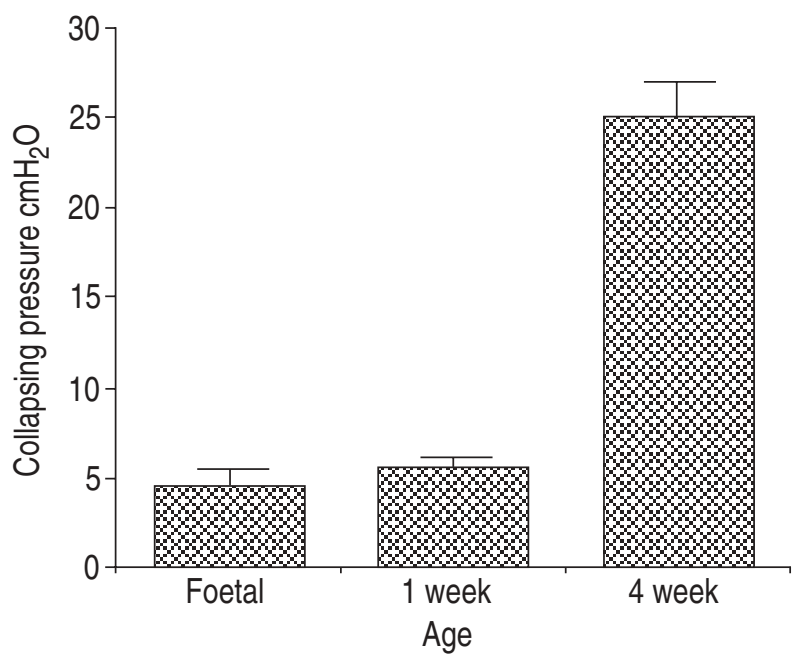

Fig. 2. - Internal closing pressures of bronchi from foetal $(n=7), 1$ week $(n=8)$ and 4 week old $(n=8)$ pigs. Internal closing pressure is the negative intraluminal pressure which produced occlusion of the bronchial lumen. Bronchi from foetal and 1 week old pigs had the same internal closing pressure, while both were closed by significantly less pressure than bronchi from 4 week old pigs $(\mathrm{p}<0.001)$.

$\left.\mathrm{cmH}_{2} \mathrm{O}\right)$ and 1 week old $\left(-5.40 \pm 0.60 \mathrm{cmH}_{2} \mathrm{O}\right)$ pigs were similar. However, intraluminal pressures fourfold more negative $\left(-24.90 \pm 1.92 \mathrm{cmH}_{2} \mathrm{O}\right)$ were required to close bronchi from 4 week old pigs $(\mathrm{p}<0.001)$ (fig. 2). External closing pressures showed a similar difference between age groups, where bronchi from 1 week old pigs closed at much lower pressures $\left(6.86 \pm 0.77 \mathrm{cmH}_{2} \mathrm{O}\right)$ than bronchi from 4 week old pigs $\left(19.80 \pm 1.50 \mathrm{cmH}_{2} \mathrm{O}\right)(\mathrm{p}<0.001)$ (fig. 3). External and internal closing pressures were not measured in the same bronchi but were comparable in animals of the same age. Carbachol precontraction increased external closing pressure by approximately 5 $\mathrm{cmH}_{2} \mathrm{O}$ in both age groups $(\mathrm{p}<0.05)$ (fig. 3 ).

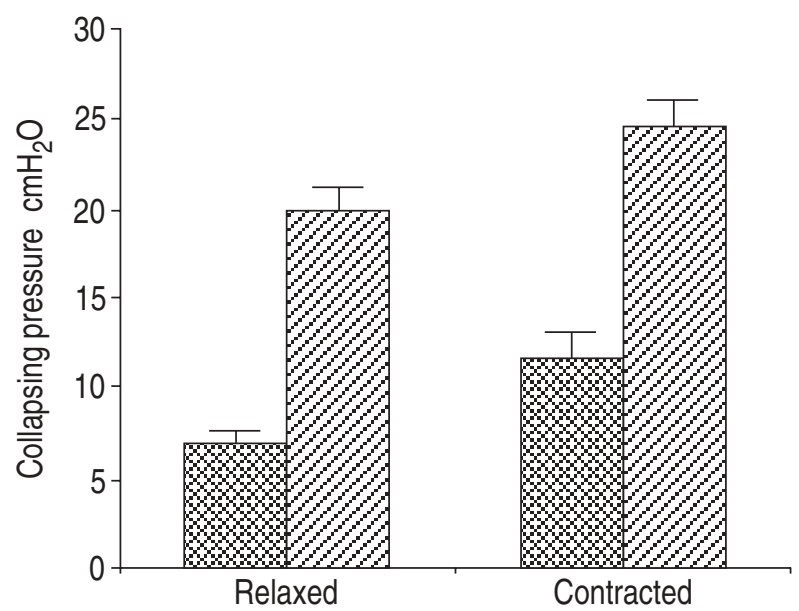

Fig. 3. - External closing pressures of bronchi from 1 week $(n=7)$ and 4 week old $(n=10)$ pigs before and during contraction with $1 \mu \mathrm{M}$ carbachol. External closing pressure was the adventitial pressure required to compress the bronchi sufficiently to close the lumen. Closing pressure was measured with the smooth muscle relaxed and with the bronchial smooth muscle contracted by $1 \mu \mathrm{M}$ carbachol. Bronchi from 1 week old pigs required significantly less pressure to occlude the lumen both in the relaxed and contracted state $(\mathrm{p}<0.001)$. Relaxed bronchi were closed by lower pressures than contracted bronchi from pigs of the same age $(\mathrm{p}<0.05)$. External and internal (see fig. 2) closing pressures were measured in separate experiments. $\square$ : 1 week old pigs; $\square$ : 4 week old pigs. 

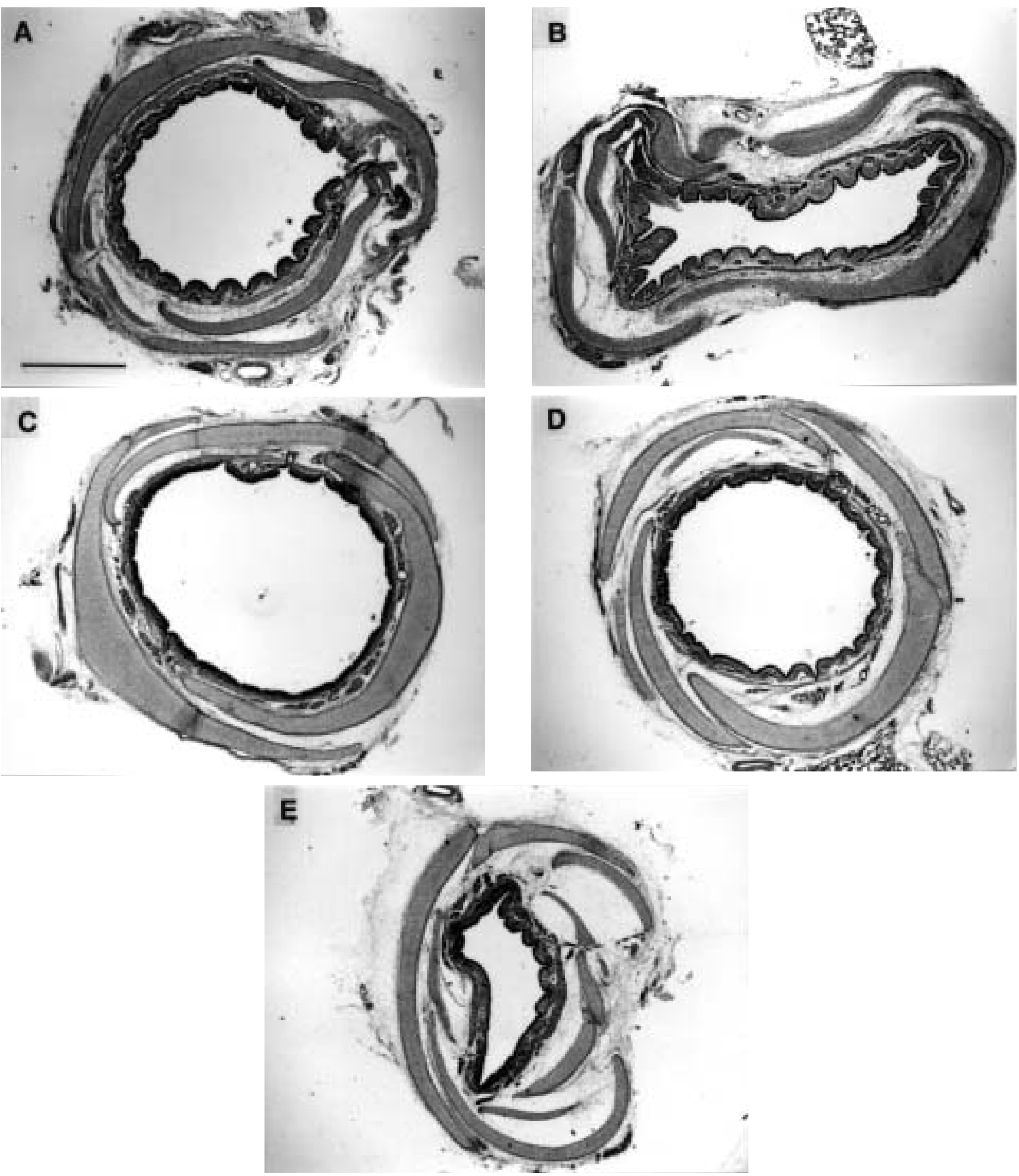

Fig. 4. - Photomicrographs of bronchi from 1 and 4 week old pigs fixed at varying intraluminal pressures. A and B) bronchi of 1 week old pigs fixed at an intraluminal pressure of +5 and $-5 \mathrm{cmH}_{2} \mathrm{O}$, respectively; $\mathrm{C}, \mathrm{D}$ and $\mathrm{E}$ ): bronchi of 4 week old pigs fixed with intraluminal pressures of $+5,-5$ and $-20 \mathrm{cmH}_{2} \mathrm{O}$, respectively. (Haematoxylin and chromatrope $2 \mathrm{R}$ stain; internal scale bar=1 $\mathrm{mm}$ ).

Histological sections of bronchi from 1 week old pigs appeared significantly deformed when fixed at $-5 \mathrm{cmH}_{2} \mathrm{O}$ (fig. 4), with a generally flattened appearance and occlusion of the lumen. The cartilage plates of 1 week old bronchi were often bent when fixed near closing pressure. In contrast, bronchi from 4 week old pigs appeared normal when fixed at an intraluminal pressure of -5 $\mathrm{cmH}_{2} \mathrm{O}$. However, when fixed at $-20 \mathrm{cmH}_{2} \mathrm{O}, 4$ week old bronchi were elliptical rather than circular in shape, and had a flattened lumen with a reduced area. Cartilage plates were seldom bent in airways from 4 week old pigs, but they were generally found to have pulled away from each other and the smooth muscle layer was often separated from the cartilage. This separation was not normally a feature of collapsed bronchi from 1 week old pigs. Serial sections showed that the bronchi from 

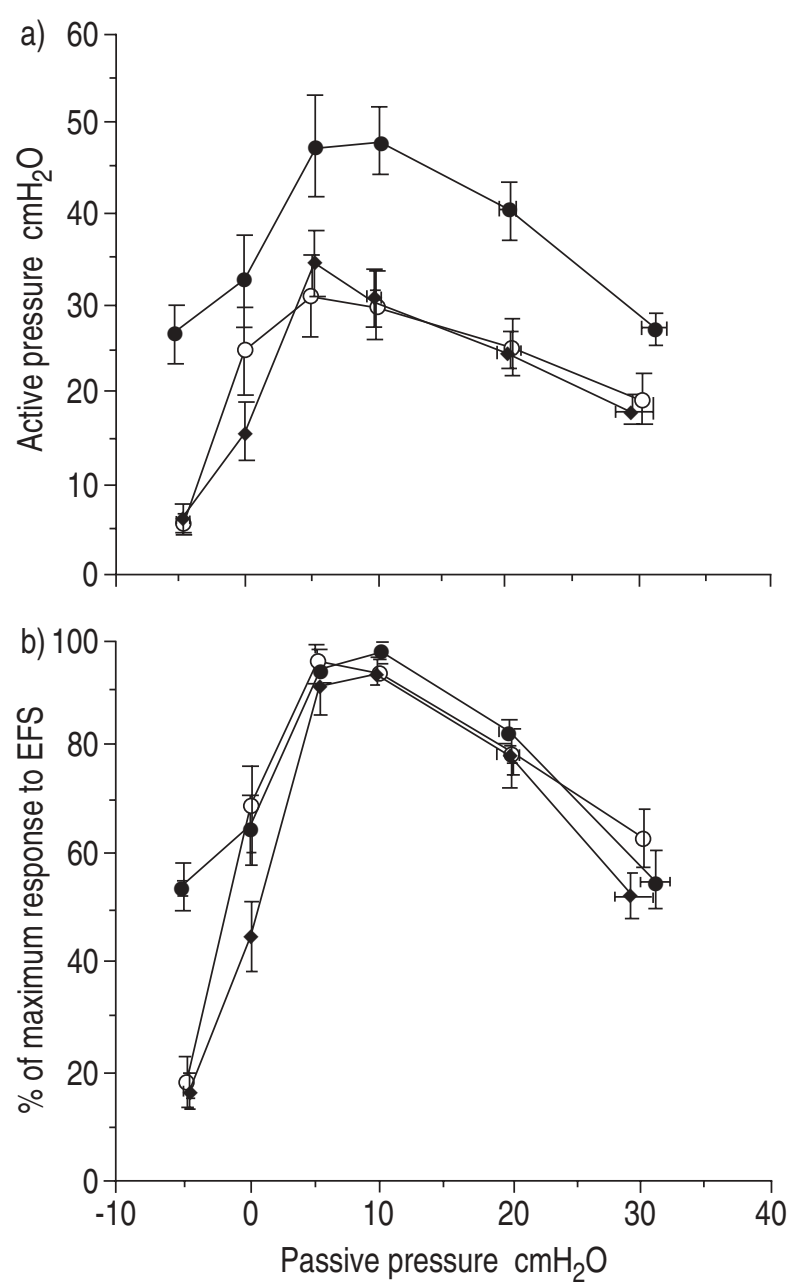

Fig. 5. - Active versus passive pressure curves for bronchi from foetal $(n=12), 1$ week $(n=8)$ and 4 week old $(n=8)$ pigs. Passive pressure was the resting intraluminal pressure before the bronchi were stimulated. Active pressure is the rise in intraluminal pressure produced by electrical field stimulation (EFS) at $70 \mathrm{~V}, 30 \mathrm{~Hz}$ with a 1 $\mathrm{ms}$ pulse width. a) Unnormalized active pressures: bronchi from 4 week old pigs produced significantly more force than bronchi from foetal or 1 week old pigs $(\mathrm{p}<0.001)$. b) Active pressure normalized for each tissue's maximum response to EFS: after normalization, increasing passive pressure above $0 \mathrm{cmH}_{2} \mathrm{O}$ has the same effect on all ages; however, foetal and 1 week old pigs generate significantly less active pressure (as a percentage of maximum) at a passive pressure of $-5 \mathrm{cmH}_{2} \mathrm{O}$. - - - : foetal pigs; $\longrightarrow \longrightarrow$ : 1 week old pigs; $\longrightarrow \bullet-$ 4 week old pigs.

each age group did not collapse uniformly, but varied in the extent of lumen occlusion along their length.

\section{Active-passive pressure}

Bronchi from 4 week old pigs produced more active pressure at all passive transmural pressures than bronchi from 1 week old and foetal pigs $(\mathrm{p}<0.001)$ (fig. 5a). Segments from all age groups produced maximum active pressure at passive intraluminal pressures of 5-10 $\mathrm{cmH}_{2} \mathrm{O}$. Changes in passive intraluminal pressure above $0 \mathrm{cmH}_{2} \mathrm{O}$ produced similar changes in active pressure production (as a percentage of maximum) in all age groups (fig. 5b). Negative pressures, in contrast, produced a more rapid decline in response to EFS in the
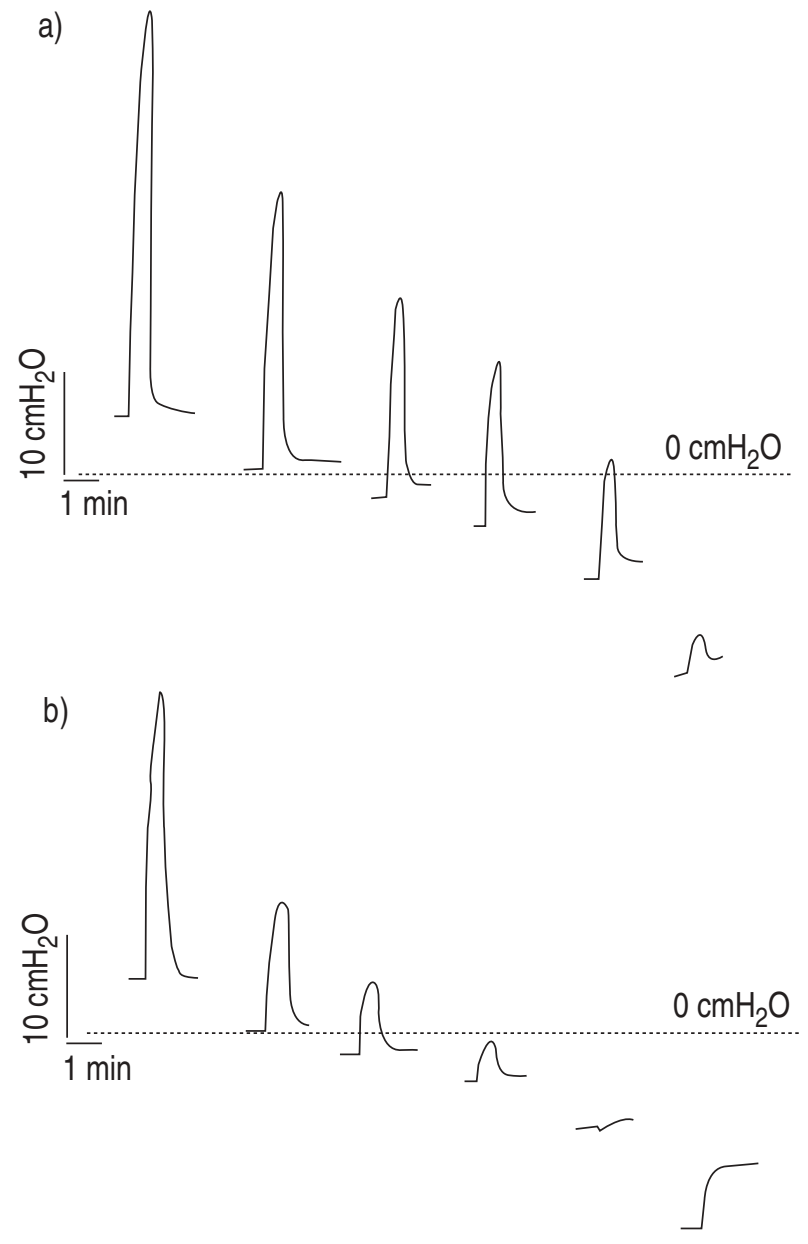

Fig. 6. - Traces of typical responses to electrical field stimulation (EFS) $(70 \mathrm{~V}, 30 \mathrm{~Hz}, 1 \mathrm{~ms}$ pulse width) for bronchi from a) 4 week old and; b) 1 week old pigs at passive intraluminal pressures of +5 , $0,-2.5,-5,-10$ and $-20 \mathrm{cmH}_{2} \mathrm{O}$. Bronchi from 4 week old pigs typically showed a steady reduction in force generation as passive pressure was reduced but, with some active pressure generation even at $-20 \mathrm{cmH}_{2} \mathrm{O}$. Bronchi from 1 week old pigs had a more rapid reduction in active pressure generation as passive pressure was reduced. Active response was abolished in bronchi from 1 week old pigs at a passive pressure of $-10 \mathrm{cmH}_{2} \mathrm{O}$. At a passive intraluminal pressure of $-20 \mathrm{cmH}_{2} \mathrm{O}$ segments from 1 week old pigs showed a large increase in luminal pressure during EFS, which was maintained after the stimulus stopped.

foetal and 1 week old pigs, compared to 4 week old pigs (figs. 5 and 6). Four week old bronchi showed a steady reduction in active force generation to at least $-20 \mathrm{cmH}_{2} \mathrm{O}$, whereas responses from 1 week old bronchi were abolished by negative intraluminal pressures greater than -5 but less than $-10 \mathrm{cmH}_{2} \mathrm{O}$ (fig. 6).

Four out of five bronchi from 1 week old pigs showed an unusual response to EFS at $-20 \mathrm{cmH}_{2} \mathrm{O}$. This response consisted of a large increase in intraluminal pressure, which was maintained even after EFS stopped (fig. 6).

\section{Videoendoscopy}

When bronchi underwent EFS at a transmural pressure of $0 \mathrm{cmH}_{2} \mathrm{O}$, the lumen narrowed in an iris like manner, remaining circular but with numerous regularly spaced deep folds in the mucosa (fig. 7A and B). When 

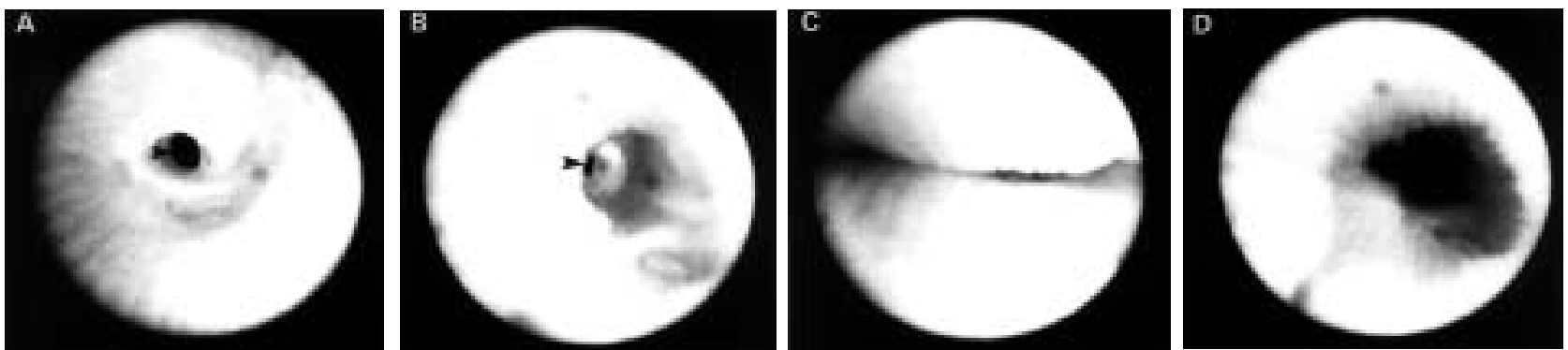

Fig. 7. - Videoendoscopy images of the lumen of the bronchus of a 1 week old pig (all images are of the same bronchus) viewed looking towards the distal end. A and B) Bronchus at $0 \mathrm{cmH}_{2} \mathrm{O}$ resting intraluminal pressure, before and during electrical field stimulation (EFS) (70 V, $30 \mathrm{~Hz}, 1 \mathrm{~ms}$ ), respectively. The black region near the centre of the field, indicated by arrows, is the lumen of the distal cannula. During EFS the proximal region of the segment has narrowed, largely obscuring the distal end bronchus. C and D) Bronchus collapsed by a resting intraluminal pressure of $-5 \mathrm{cmH}_{2} \mathrm{O}$, before and during EFS $(70 \mathrm{~V}, 30 \mathrm{~Hz}, 1 \mathrm{~ms})$, respectively. Closure of the bronchus has occurred in the foreground near the endoscope and in a flat plane. During EFS the flatted lumen of the closed bronchus became more circular in shape, partially opening the lumen. This bronchus produced the greatest opening during EFS observed in closed bronchi and is atypical of the small amount of opening usually seen. No scale is shown, as the scale changes with distance from the endoscope: the edge of the field of view is closest to the endoscope and the centre furthest from it.

Table 2. - Human bronchi: size and internal collapse pressure of human bronchial segments

\begin{tabular}{lccccc}
\hline $\begin{array}{l}\text { Bronchial } \\
\text { segment }\end{array}$ & Sex & Age & $\begin{array}{c}\text { Distal } \\
\text { internal } \\
\text { diameter } \\
\text { mm }\end{array}$ & $\begin{array}{c}\text { Lumen } \\
\text { volume }\end{array}$ & $\begin{array}{c}\text { Internal } \\
\text { closing } \\
\text { pressure } \\
\text { cmH }_{2} \mathrm{O}\end{array}$ \\
\hline 1 & F & $4 \mathrm{mo}$ & 1.8 & 0.10 & -16.0 \\
2 & $\mathrm{M}$ & $2 \mathrm{mo}$ & - & 0.01 & -9.7 \\
3 & - & - & 2.2 & 0.05 & -4.0 \\
4 & $\mathrm{M}$ & $3 \mathrm{mo}$ & 1.6 & 0.05 & -10.5 \\
5 & $\mathrm{M}$ & $3 \mathrm{mo}$ & - & 0.04 & -11.4 \\
6 & $\mathrm{M}$ & $1 \mathrm{mo}$ & 1.4 & 0.03 & -12.5 \\
7 & $\mathrm{M}$ & $1 \mathrm{wk}$ & 2.2 & - & -11.2 \\
8 & $\mathrm{M}$ & $5 \mathrm{mo}$ & 1.6 & 0.03 & -16.0 \\
\hline Mean & & & & & -11.4 \\
SEM & & & & & 1.4 \\
\hline
\end{tabular}

All human bronchi were from infants who died of sudden infant death syndrome (SIDS). Luminal volume is the volume of the bronchial segment lumen with no transmural pressure difference. Internal closing pressure is the negative intraluminal pressure required to occlude the bronchial lumen. M: male; F: female.

intraluminal pressure was reduced to closure, the lumen appeared flattened along a single plane, rather than circular, and mucosal folding was not prominent (fig. 7C). Closure of the bronchial lumen appeared to occur first at a point, with the lumen on both sides of this point narrowed but still patent. EFS of closed bronchi produced a modest opening of the lumen, visible through the endoscope (fig. 7D) in 5 of 6 segments studied, and a generally more circular appearance to the lumen. However, this dilation (of the closed lumen) was slight. Both the constrictor response to EFS at $0 \mathrm{cmH}_{2} \mathrm{O}$ and the dilation of closed bronchi were inhibited by atropine.

\section{Human bronchi}

The internal closing pressure, lumen volume and distal internal diameter, of the human bronchi are presented in table 2, together with details of the infants sex and age. Histological sections of closed bronchi from human infants showed a flattened lumen and bending of the membranous airway wall between cartilage plates.
Neither bending of the cartilage plates nor separation of the components of the airway wall was apparent in histological sections of closed human bronchi.

\section{Discussion}

\section{Pressure induced airway closure}

Bronchi from immature animals (late term foetal and 1 week old pigs) were approximately four times more susceptible to airway closure than bronchi from more mature animals (4 week old pigs). Immature bronchi were more susceptible to collapse, regardless of whether luminal or adventitial pressure was changed. The pattern of maturational change in closing pressures was similar to the maturational changes in compliance, where bronchi from late-term foetal and 1 week old pigs are more compliant than bronchi from 4 week old pigs (unpublished data).

Bronchi from human infants were also closed by relatively small transmural pressures, suggesting that infant airways could be more vulnerable to collapse. Compression of infant airways could occur during forced expiration, such as crying and coughing, or while performing a Valsalva manoeuvre (during defaecation [17]). Increased collapsibility of bronchi can elevate closing volume and reduce maximum expiratory flow [17-20]. Both airway closure [21], and flow limitation [22] have been observed in some healthy infants during normal tidal breathing. Collapse of peripheral airways during repeated attempts to clear an obstruction [21], or prolonged expiratory apnoea [23] have been postulated as factors contributing to the SIDS. However, the transpulmonary pressure and lung volume at which airway closure occurs is dependent on the forces applied to bronchi, for example from parenchymal interdependence, as well as the mechanical properties of the bronchi themselves [1821]. Elastic recoil pressures of immature lungs are low compared to adults $[19,21,24]$, suggesting that the forces resisting bronchial closure may be less in the infant than the adult.

Because of lung growth during development, bronchi of the same size and generation cannot be compared among different ages. Changing airway diameter will alter the tension in the airway wall according to the law 
of Laplace. In this study, bronchi of similar internal diameters were compared to minimize the influence of Laplace's law. This meant that bronchi from younger animals were taken from more proximal regions of the stem bronchus (table 1). However, the porcine stem bronchus has a similar composition, e.g. in proportion of cartilage, along its length (unpublished observations) and regional differences in compliance, reported by others [25], cannot explain the increased collapsibility of the immature bronchi that we have reported here.

\section{Structural basis of airway collapse}

Bronchi from 1 and 4 week old pigs appeared collapsed when fixed at intraluminal pressures of -5 and $-20 \mathrm{cmH}_{2} \mathrm{O}$, respectively, which corresponds well with the measured closing pressures. Human bronchi also showed evidence of collapse when fixed at a transmural closing pressure close to their internal closing pressure. Hence, the histological appearance of the bronchi is in accord with the novel method that we have used to assess bronchial closure in vitro.

Collapsed bronchi from 1 week old pigs showed bending of the cartilage plates but little separation of the smooth muscle from the cartilage or between cartilage plates. In contrast, cartilage plates of collapsed bronchi from 4 week old pigs showed little bending, but the smooth muscle and underlying structures were often pulled away from the cartilage. The cartilage plates were also separated from each other in bronchi from 4 week old pigs that were fixed at $-20 \mathrm{cmH}_{2} \mathrm{O}$. This separation of airway wall structures seen in four week old bronchi has previously been observed in sections of adult cat bronchi fixed with a negative intraluminal pressure [6]. Closure of immature bronchi may occur at lower transmural pressures because the cartilage plates are more pliable [26], and bend easily under low pressures. In the 4 week old pigs, increased cartilage stiffness may prevent bending of the plates, and collapse may not occur until the transmural pressure is high enough to cause separation of the components of the airway wall. Human infant bronchi showed neither wall separation nor cartilage bending, with collapse appearing to occur by bending between the cartilage plates. The membranous regions, of the human bronchi, between plates of cartilage, appear to act as a hinge allowing the airway to flatten during collapse.

Endoscopy and histology showed that closure of the lumen was focal, not uniform along the bronchus, which means that bronchi will close while the lumen is still partly filled. Focal closure of bronchi implies that the (in vitro) closing pressure of a bronchus cannot be predicted from the pressure-volume curve of that airway, as closure will occur before the pressure-volume curve reaches zero volume. The interpretation of bronchial compliance curves at negative intraluminal pressures may be complicated by focal collapse and fluid/gas trapping in bronchial segments.

\section{Effect of smooth muscle tone on airway stability}

The effect of smooth muscle tone on the collapsibility of immature bronchi has not been studied previously.
Closing pressures were significantly increased by precontraction, although this increase was small compared to the effect of tone on tracheal collapse $[4,5,6,9,10]$. Structural differences between trachea and bronchi may explain why smooth muscle contraction was less effective at stabilizing bronchi than trachea. The trachealis pulls the ends of the cartilage together forming a solid cylinder $[6,7]$. Bronchial smooth muscle tone appears unable to produce a similar solid ring of cartilage. This may be due to the multiple joints between cartilage plates or because bronchial smooth muscle is not directly attached to cartilage.

Although the increase in closing pressure produced by carbachol was small in absolute terms, an increase of about $5 \mathrm{cmH}_{2} \mathrm{O}$ represents an approximate doubling in the closing pressure of the immature bronchi. Hence, constriction of bronchial smooth muscle may be relatively more important for stabilizing immature than mature bronchi.

Effect of bronchial stability on preload and smooth muscle operating length

The ability of airway smooth muscle to generate tone is itself influenced by the transmural pressure and airway compliance [13], as these factors affect the preload applied to the muscle. Tracheal segments treated with papain, require higher passive transmural pressures to stretch the trachealis to optimum length [13]. Furthermore, after papain, the force generated by trachealis contraction changes more sharply as the resting transmural pressure is altered, implying that the smooth muscle operating length is more dependent on the resting pressure [13]. Due to their higher compliance, we expected force generation by immature airways to be more dependent on the resting transmural pressure than bronchi from older animals. However, the active versus passive pressure curves for all age groups were the same for positive intraluminal pressures. One possible explanation for this could be a change in the length-tension properties of bronchial smooth muscle during development that compensated for the change in compliance.

Although the active-passive pressure curves were similar at positive pressures, immature bronchi were unable to maintain contraction at negative intraluminal pressures. This impairment of force generation in the younger pigs was probably due to bronchial collapse at negative intraluminal pressures.

\section{Bronchial dilation produced by smooth muscle contrac- tion}

Bronchi from 1 week old pigs showed an unusual response to EFS at an intraluminal pressure of $-20 \mathrm{cmH}_{2} \mathrm{O}$ (see Results), where the detected pressure increased during EFS and remained elevated after stimulation was discontinued. We hypothesized that any opening of the lumen, however small, during EFS would result in pressure equalising between the two ends of the segment, producing an increase in the detected intraluminal pressure that would be sustained after stimulation ended. In response to EFS, the closed lumen became more circular producing an opening of the lumen visible with endoscopy. 
Dilation of the closed bronchi was atropine sensitive, indicating that the dilation was produced by increased muscle tone. The degree of luminal dilation produced in these experiments was generally small, and probably insufficient to allow significant flow. However, this extreme case may be an example of the potential protective effect of excitatory neurotransmission to airways.

This study has demonstrated that closure of large conducting bronchi from immature animals and human infants can occur with a transmural pressure difference less than $10 \mathrm{cmH}_{2} \mathrm{O}$. The low pressure difference that can occlude immature bronchi suggests that these airways could be easily compressed during respiratory manoeuvres, such as crying or coughing. Closure of the lumen and fluid/gas trapping in bronchi, in vitro, may complicate the interpretation of bronchial pressure-volume curves. Bronchial smooth muscle tone has some influence on bronchial closure, which is relatively more important for the immature animals.

Acknowledgements: The authors thank the Western Australian State Coroner and the staff of the forensic pathology service for help with obtaining human tissues.

\section{References}

1. Bhutani VK, Rubenstein SD, Shaffer TH. Pressure-volume relationships of tracheae in fetal newborn and adult rabbits. Respir Physiol 1981; 43: 221-231.

2. Croteau JR, Cook CD. Volume-pressure and lengthtension measurements in human tracheal and bronchial segments. J Appl Physiol 1961; 16: 170-172.

3. Shaffer TH, Bhutani VK, Wolfson MR, Penn RB, Tran $\mathrm{NN}$. In vivo mechanical properties of the developing airway. Pediatr Res 1989; 25: 143-146.

4. Penn RB, Wolfson MR, Shaffer TH. Effect of tracheal smooth muscle tone on collapsibility of immature airways. J Appl Physiol 1988; 65: 863-869.

5. Coburn RF, Thornton D, Arts R. Effect of trachealis muscle contraction on tracheal resistance to airflow. $J$ Appl Physiol 1972; 32: 397-403.

6. Olsen CR, Stevens AE, Pride NB, Staub NC. Structural basis for decreased compressibility of constricted tracheae and bronchi. J Appl Physiol 1967; 23: 35-39.

7. Palombini B, Coburn RF. Control of the compressibility of the canine trachea. Respir Physiol 1972; 15: 365-383.

8. Begis D, Delpuech C, Le Tallec P, Loth L, Thiriet M, Vidrascu M. A finite-element model of tracheal collapse. J Appl Physiol 1988; 64: 1359-1368.

9. Bhutani VK, Koslo RJ, Shaffer TH. The effect of tracheal smooth muscle tone on neonatal airway collapsibility. Pediatr Res 1986; 20: 492-495.
10. Olsen CR, Stevens AE, Mcllroy MB. Rigidity of tracheae and bronchi during muscular constriction. J Appl Physiol 1967; 23: 27-34.

11. Gunst SJ, Stropp JQ. Pressure-volume and length-stress relationships in canine bronchi in vitro. J Appl Physiol 1988; 64: 2522-2531.

12. Koslo RJ, Bhutani VK, Shaffer TH. The role of tracheal smooth muscle contraction on neonatal tracheal mechanics. Pediatr Res 1986; 20: 1216-1220.

13. Moreno RH, Paré PD. Intravenous papain-induced cartilage softening decreases preload of tracheal smooth muscle. J Appl Physiol 1989; 66: 1694-1698.

14. Mitchell HW, Willet KE, Sparrow MP. Perfused bronchial segment and bronchial strip: narrowing $v s$ isometric force by mediators. J Appl Physiol 1989; 66: 2704-2709.

15. Mitchell HW, McFawn PK, Sparrow MP. Increased narrowing of bronchial segments from immature pigs. Eur Respir J 1992; 5: 207-212.

16. Mitchell HW, Sparrow MP. Videoimaging of lumen narrowing: muscle shortening and flow responsiveness in isolated bronchial segments of the pig. Eur Respir $J$ 1994; 7: 1317-1325.

17. Sotomayor JL, Godinez RI, Borden S, Wilmott RW. Large airway collapse due to acquired tracheobronchomalacia in infancy. Am J Dis Child 1986; 140: 367371.

18. Jones JG, Fraser RB, Nadel JA. Effect of changing airway mechanics on maximum expiratory flow. J Appl Physiol 1975; 38: 1012-1021.

19. Bryan AC, Mansell AL, Levison H. Development of the mechanical properties of the respiratory system. In: Hodson WA, ed. Development of the Lung. Marcel Dekker Inc., New York, USA, 1977; pp. 445-468.

20. Macklem PT, Fraser RG, Broen WG. Bronchial pressure measurements in emphysema and bronchitis. J Clin Invest 1965; 44: 897-905.

21. Martinez FD. Sudden infant death syndrome and small airway occlusion: facts and a hypothesis. Pediatrics 1991; 87: 190-198.

22. Young S, Arnott J, Le Souef PN, Landau LI. Flow limitation during tidal expiration in symptom-free infants and the subsequent development of asthma. J Pediatr 1994; 124: 681-688.

23. Southall DP. Role of apnea in the sudden infant death syndrome: a personal view. Pediatrics 1988; 80: 73-84.

24. Mansell AL, McAteer AL, Pipkin AC. Maturation of interdependence between extra-alveolar and lung parenchyma in piglets. Circ Res 1992; 71: 701-710.

25. Martin HB, Proctor DF. Pressure-volume measurements on dog bronchi. J Appl Physiol 1958; 13: 337-343.

26. Penn RB, Wolfson MR, Shaffer TH. Developmental differences in tracheal cartilage mechanics. Pediatr Res 1989; 26: 429-433. 